\begin{tabular}{|c|c|c|}
\hline \multirow{3}{*}{$\begin{array}{r}\text { Case Reports in } \\
\text { Gastroenterology }\end{array}$} & \multirow{2}{*}{\multicolumn{2}{|c|}{ Case Rep Gastroenterol 2016;10:596-599 }} \\
\hline & & \\
\hline & $\begin{array}{l}\text { DOI: 10.1159/000448071 } \\
\text { Publisned online: October 18, } 2016\end{array}$ & $\begin{array}{l}\text { (C) } 2016 \text { The Author(s) } \\
\text { Published by S. Karger AG, Basel } \\
\text { www.karger.com/crg }\end{array}$ \\
\hline & \multicolumn{2}{|c|}{$\begin{array}{l}\text { This article is licensed under the Creative Commons Attribution-NonCommercial } 4.0 \\
\text { International License (CC BY-NC) (http://www.karger.com/Services/OpenAccessLicense). } \\
\text { Usage and distribution for commercial purposes requires written permission. }\end{array}$} \\
\hline
\end{tabular}

\title{
Febrile Neutropenia with Thrombocytopenia after Infliximab Induction in a Patient with Ulcerative Colitis
}

\author{
Gustavo Gomez $^{\mathrm{a}}$ Shifa Umar ${ }^{\mathrm{b}} \quad$ Mohammad Bilal $^{\mathrm{b}} \quad$ Cristina Strahotin $^{\mathrm{a}}$ \\ Kofi Clarke \\ ${ }^{a}$ Division of Gastroenterology, Hepatology and Nutrition, Allegheny Health Network, \\ Pittsburgh, Pa., USA; ${ }^{\circ}$ Department of Internal Medicine, Allegheny Health Network, \\ Pittsburgh, Pa., USA
}

\section{Keywords}

Ulcerative colitis · Febrile neutropenia · Thrombocytopenia · Infliximab

\begin{abstract}
A 34-year-old female with left-sided ulcerative colitis (UC) developed severe febrile neutropenia/thrombocytopenia soon after infliximab induction therapy. There was no other plausible cause of the cell line abnormalities other than an accurate temporal association with infliximab administration. Supportive care, broad-spectrum antibiotic, and single dose of filgrastim was given on day 5 of admission due to persistently low absolute neutrophil count and fevers. The cell lines recovered, fever resolved and the patient made a complete clinical recovery. Clinicians should be aware of this potential life-threatening infliximab side effect previously unreported in adults with UC.

(C) 2016 The Author(s)

Published by S. Karger AG, Basel
\end{abstract}

\section{Introduction}

Infliximab, a chimeric monoclonal antibody, binds to tumor necrosis factor (TNF)- $\alpha$, thereby interfering with its endogenous activity. It is indicated for induction and mainte- 
nance of clinical and endoscopic remission of moderate to severe ulcerative colitis (UC) that is refractory to conventional therapy (i.e., aminosalicylic acid [5-ASA] products, steroids, and immunomodulators).

Well-known adverse effects of infliximab include infusion reactions, cutaneous lesions (including psoriasis), cardiac arrhythmias, demyelinating disease, development of autoantibodies, reactivation of hepatitis B and tuberculosis infections, and increased risk of developing T-cell lymphomas. Hematological abnormalities have been infrequently observed in patients treated with infliximab. Febrile neutropenia has been previously reported with infliximab, but in the rheumatologic and pediatric population $[1,2]$.

We report a case of an adult patient with UC treated with infliximab who presented with severe febrile neutropenia and thrombocytopenia. In addition, she had anemia, likely from acute blood loss related to UC.

\section{Case Presentation}

A 34-year-old female with a 3-year history of left-sided UC presented to the emergency department with a 3-week history of intermittent fevers up to $102^{\circ} \mathrm{F}$. The fever was associated with chills, nausea, non-bilious/non-bloody emesis, anorexia, and a sharp, constant, left lower-quadrant pain. The pain radiated to her lower back and preceded the onset of fevers by 3 weeks. Her UC, which was initially unresponsive to topical 5-ASA compounds, had been in clinical remission on 6-mercaptopurine (6-MP) and oral mesalamine therapy for 2 years. Six weeks before presentation, she developed abdominal discomfort and intermittent bloody diarrhea up to 10 times a day. Colonoscopy by her local gastroenterologist 4 weeks before admission showed active disease of her distal colon. Prior to initiation of TNF- $\alpha$ inhibitor, the patient had a normal complete blood count, normal comprehensive metabolic panel, negative hepatitis B surface antigen, and negative purified protein derivative testing. She received the first two induction doses of $5 \mathrm{mg} / \mathrm{kg}$ of infliximab prior to admission to our institution. Other home medications included hydrocodone/acetaminophen and ondansetron on an as-needed basis.

On examination, the patient was tachycardic (124 beats per minute) and febrile $\left(101.4^{\circ} \mathrm{F}\right)$. In addition, she looked pale, and was diaphoretic. There was moderate tenderness to palpation of her left lower quadrant without rebound tenderness. The rest of the clinical examination was normal. Laboratory testing showed white cell count of $2.63 \times 10^{3} / \mu \mathrm{L}$ (normal range 4.4-11.3 $\times 10^{3} / \mu \mathrm{L}$ ) with an absolute neutrophil count (ANC) of $0.18 \times 10^{3} / \mu \mathrm{L}$ (normal range 2.0-9.3 $\times 10^{3} / \mu \mathrm{L}$ ), hemoglobin of $7.6 \mathrm{~g} / \mathrm{dL}$ (normal range 12.3-15.3 g/dL), platelet count of $128 \times 10^{3} / \mu \mathrm{L}$ (normal range $145-445 \times 10^{3} / \mu \mathrm{L}$ ), C-reactive protein of 29.5 $\mathrm{mg} / \mathrm{dL}$ (normal $<0.8 \mathrm{mg} / \mathrm{dL}$ ), and erythrocyte sedimentation rate of $>140 \mathrm{~mm} / \mathrm{h}$ (normal 0$15 \mathrm{~mm} / \mathrm{h}$ ). She was started on empiric intravenous (IV) vancomycin, cefepime, and metronidazole pending microbiology results. IV vancomycin and metronidazole were discontinued after negative infectious workup. Blood, urine, and respiratory cultures were consistently and serially negative during her hospital stay. Viral serologies for Epstein-Barr virus, HIV, influenza, hepatitis, $\beta$-D-glucan assay, toxoplasma, and tuberculosis were all negative or within the normal range. Stool culture, ova, and parasites, and stool for Clostridium difficile testing by PCR were also negative. There was a mild elevation in cytomegalovirus (CMV) PCR titters; however, CMV IgM antibody was negative. Computerized tomography scan of the chest and transthoracic echocardiogram were unrevealing. Computerized tomography scan of the abdomen and pelvis with IV and per os contrast revealed circumferential wall thicken- 
ing and mucosal hyperenhancement involving the descending, sigmoid colon and rectum. A repeat colonoscopy was not performed because of severe neutropenia. The patient continued to have a persistently low ANC for the next 5 days after admission, along with febrile episodes ranging from 101 to $102^{\circ} \mathrm{F}$. A single dose of subcutaneous filgrastim was administered on day 5 of admission, resulting in recovery of her neutrophil count over 3 days along with resolution of fever. Platelet count normalized prior to discharge. The anemia was attributed to active lower gastrointestinal bleeding and active UC.

\section{Discussion}

Infliximab is a chimeric TNF- $\alpha$ inhibitor approved by the US Food and Drug Administration for the treatment of moderate to severe UC. It is indicated in patients who have failed or are unresponsive to conventional therapy with 5-ASA, immunomodulators (6-MP and azathioprine), and steroids/steroid-dependent disease [3]. In a systematic review by Lawson et al. [4], infliximab was effective in inducing and maintaining clinical remission, promoting mucosal healing, and reducing the need for colectomy in the short term.

Nonmalignant hematological abnormalities associated with infliximab are rare. There are a few reports in individuals who have received infliximab for rheumatologic conditions. Previous reports on blood dyscrasias in adults with inflammatory bowel disease treated with anti-TNF- $\alpha$ molecules were largely in patients with Crohn's disease.

In a systematic review by Bessissow et al. [5], of over 200 patients who developed nonmalignant hematological complications of anti-TNF- $\alpha$ therapy, there were a few inflammatory bowel disease cases identified. Three out of $15(20 \%)$ cases of significant thrombocytopenia $\left(<50 \times 10^{3} / \mu \mathrm{L}\right)$ were attributed to infliximab, occurring between 1 and 32 weeks after drug exposure. All three were patients with Crohn's colitis. In addition, 2 out of 111 (1.8\%) cases developed severe neutropenia (ANC $<0.5 \times 10^{3} / \mu \mathrm{L}$ ) 2-4 weeks after initial infusion therapy of the chimeric molecule [5]. These cases were remarkable for either thrombocytopenia or neutropenia but not both.

Data from clinical trials reported by the drug manufacturer indicate an incidence of 1.1$5.7 \%$ of moderate neutropenia and $0.5-1.9 \%$ of non-clinically significant thrombocytopenia associated with infliximab [6,7].

Several theories have been postulated as possible explanations for TNF- $\alpha$ inhibitorinduced neutropenia and thrombocytopenia. These include direct cytokine disruption at the bone marrow level impairing proper hematopoiesis and granulocyte-bound antibody and neutrophil-specific (CD-16)-bound antibody (anti-NA) development triggered by infusion of infliximab leading to peripheral cell destruction $[1,5]$. Infliximab-induced anti-platelet antibodies in settings of an idiopathic thrombocytopenic purpura-like illness and direct platelet destruction mediated by improperly handled immune complexes are two of the theories reported as potential causes of the thrombocytopenia seen in this group of patients [8].

Our patient presented with thrombocytopenia and neutropenia, occurring 5 days after the second dose of infliximab. Other than a positive PCR assay for CMV with negative IgM antibodies, comprehensive infectious workup was negative. The negative IgM serologies against CMV are not consistent with active viral replication.

Concomitant use of 6-MP could have been a possible culprit. However, the patient's complete blood count prior to infliximab initiation was within the normal range while on 6MP. There was no prior exposure to sulfasalazine, which has been associated with blood dyscrasias. 
Possible limitations of our diagnosis include the absence of bone marrow sampling and additional autoimmune workup. However, given the temporal relationship between receiving infliximab and her clinical improvement after stopping infliximab, her presentation is likely related to infliximab. Based on the Naranjo algorithm, our patient's clinical and laboratory findings were rendered as possible adverse drug reactions caused by infliximab therapy [9].

To the best of our knowledge, there is one previous case describing severe neutropenia in a pediatric patient with UC treated with infliximab thought to be secondary to granulocyte-bound antibodies and anti-NA antibodies [2]. That patient did not have concomitant thrombocytopenia.

There are no data on the need and when to monitor for blood cytopenias in UC patients receiving infliximab. Perhaps it is prudent to monitor complete blood counts during the induction phase of infliximab therapy.

It is important for the clinician to be aware of this serious and potentially lifethreatening side effect of infliximab, previously unreported in adults with UC. Careful monitoring with consideration of discontinuation of infliximab should be discussed when decreasing neutrophil counts are observed soon after initiation of treatment.

\section{Ethics Statement}

Informed consent was obtained.

\section{Disclosure Statement}

The authors have no financial disclosures or conflicts of interest relevant to the manuscript.

\section{References}

1 Favalli EG, Varenna M, Sinigaglia L: Drug-induced agranulocytosis during treatment with infliximab in enteropathic spondyloarthropathy. Clin Exp Rheumatol 2005;23:247-250.

-2 Sherlock ME, Bandsma R, Ota K, Kirby-Allen M, Griffiths AM: Severe neutropenia following infliximab treatment in a child with ulcerative colitis. Inflamm Bowel Dis 2011;17:E17-E18.

-3 Reinisch W, Assche GV, Befrits R, et al: Recommendations for the treatment of ulcerative colitis with infliximab: a gastroenterology expert group consensus. J Chrons Colitis 2012;6:248-258.

4 Lawson MM, Thomas AG, Akobeng AK: Tumor necrosis factor alpha blocking agents for induction of remission in ulcerative colitis. Cochrane Database Syst Rev 2006;3:CD005112.

5 Bessissow M, Renard I, Hoffman S, et al: Review article: non-malignant haematological complications of anti-tumor necrosis factor alpha therapy. Aliment Pharmacol Ther 2012;36:312-323.

6 Data on file (Protocol C0168T47; 2004). Janssen Biotech, Inc., Horsham, Pa., USA.

7 Data on file (ISS; 2005, pp 134-136). Janssen Biotech, Inc., Horsham, Pa., USA.

-8 Selby LA, Hess D, Shashidar H, de Villiers WJ, Selby LA: Crohn's disease, infliximab and idiopathic thrombocytopenic purpura. Inflamm Bowel Dis 2004;10:698-700.

$\checkmark 9$ Naranjo CA, Busto U, Sellers EM, et al: A method for estimating the probability of adverse drug reactions. Clin Pharmacol Ther 1981;30:239-245. 